\title{
NITRATE REDUCTION BY REDOX-ACTIVATED, POLYDIALLYLDIMETHYLAMMONIUM-EXCHANGED FERRUGINOUS SMECTITE
}

\author{
Kai $\mathrm{Su}^{1,2}$, Adi Radian ${ }^{3}$, Yael Mishael ${ }^{3}$, Lizhong Yang $^{2}$, and Joseph W. Stucki ${ }^{1, *}$ \\ ${ }^{1}$ University of Illinois, Urbana, Illinois, USA \\ ${ }^{2}$ Southwest Jiaotong University, Chengdu, China \\ ${ }^{3}$ Hebrew University of Jerusalem, Rehovot, Israel
}

\begin{abstract}
Nitrate is linked to chronic human illness and to a variety of environmental problems, and continues to be a contaminant of concern in soils and natural waters. Improved methods for nitrate abatement, thus, are still needed. The purpose of this study was to assess the potential for redox-modified, iron-bearing clay minerals to act as nitrate decontamination agents in natural environments. The model clay mineral tested was ferruginous smectite (sample SWa-1) exchanged with either sodium $\left(\mathrm{Na}^{+}\right)$or polydiallyldimethylammonium chloride (poly-DADMAC). Structural iron ( $\mathrm{Fe}$ ) in SWa-1 was in either the oxidized or reduced state. Little nitrate uptake was observed in the $\mathrm{Na}^{+}-\mathrm{SWa}-1$, which was attributed to coulombic repulsion between the basal surfaces of the smectite and the nitrate anion. The addition of the DADMAC to the SWa-1 reversed the electrostatic charge manifested at the smectite surface from negative to positive, as measured by the zeta $(\zeta)$ potential. The positively charged poly-DADMAC-SWa-1 yielded high nitrate uptake due to coulombic attraction in both the oxidized and reduced states of the Fe in the SWa-1. The presence of reduced structural Fe(II) in the positively charged poly-DADMAC-SWa-1 enabled a chemical reduction reaction with the nitrate to produce nitrite. The amounts of nitrite found in solution, however, failed to account for all of the Fe(II) oxidized, so other $\mathrm{N}$ reduction products may also have formed or perhaps nitrite was also present in the adsorbed phase. The effects of other complexities, such as polymer configuration at the surface, also need further investigation. The results do clearly establish abiotic nitrate reduction to nitrite and possibly other reduction products. The combination of bacterial activity in soils and sediments, which is known to reduce structural Fe in smectites, and the abundance of organic cations in soil organic matter creates an environment where reversed-charge smectite could exist in nature. This represents a potentially effective system for mitigating harmful effects of nitrate in soils, sediments, groundwater, and surface water.
\end{abstract}

Key Words-Iron, Nitrate, Nitrite, Polycation Organoclays, Polycation-exchanged Smectite, Redox, Reduction, Smectite.

\section{INTRODUCTION}

Nitrogen is one of the most abundant chemical elements in the environment and is a key component in the metabolic processes of plants and animals. Increasing anthropogenic activity has substantially altered the cycling of various forms of nitrogen and has contributed to diverse environmental problems (Camargo and Alonso, 2006). Increased nitrogen in water reservoirs causes acidification by nitrate and nitric acid and instigates biotic impoverishment. This nitrogen eutrophication of aquatic ecosystems results in dangerously low dissolved oxygen concentrations, adverse effects on aquatic life and human health, and can result in hypoxia, birth defects, and cancer (Camargo and Alonso, 2006). As a result, the US Environmental Protection Agency and the World Health Organization have set regulatory levels of $\mathrm{N}$-nitrate and $\mathrm{N}$-nitrite in drinking water to $10 \mathrm{mg} / \mathrm{L}$ and $1 \mathrm{mg} / \mathrm{L}$, respectively (EPA, 1986; WHO, 1996). The role of soil constituents

\footnotetext{
* E-mail address of corresponding author: jstucki@illinois.edu DOI: $10.1346 / C C M N .2012 .0600503$
}

in controlling nitrogen fate (leaching and accumulation in soil) is, therefore, of major importance.

The vast majority of the work done to elucidate the nitrogen cycle in soils has focused on microbial processes, mainly the degradation and dissimilation of nitrate to ammonium. The degradation of nitrate to nitrite, di-nitrogen, and ammonium is traditionally considered to occur under anaerobic conditions with $>60$ identified genera of denitrifying microorganisms (bacteria, archaea, fungi, and other eukaryotes) (Tiedje, 1988). Another well known pathway is the assimilation into algal or microbial biomass of solubilized nitrate passing over sediments, to produce organic $\mathrm{N}$ that may be re-mineralized later (Tiedje, 1988; Burgin and Hamilton, 2007). Overall, current knowledge of the biotic production and reduction of nitrogen species has been very well documented (Tiedje, 1988; Rivett et al., 2008; Baggs, 2011). Estimates of microbial processes, however, account for only about half of the total nitrate loss from soils (Seitzinger, 1988), which could point to other less explored pathways of nitrate reduction, including abiotic processes.

The reduction of nitrate coupled to Fe cycling may take place through both biotic and abiotic pathways; 
$\mathrm{Fe}(\mathrm{II})$ is thought to be able to reduce nitrate to nitrite, which then reacts rapidly to produce $\mathrm{N}_{2}$ or binds with organic substances to produce dissolved organic nitrogen (Davidson et al., 2003; Burgin and Hamilton, 2007). Indeed, nitrate has been shown to be directly reduced by elemental Fe (Siantar et al., 1996; Huang et al., 1998; Till et al., 1998; Devlin et al., 2000; Alowitz and Scherer, 2002; Westerhoff, 2003; Miehr et al., 2004; Sohn et al., 2006) and catalytically reduced by Fe(II) in the presence of divalent metals such as $\mathrm{Cu}$ (II) bound to the surface of Fe (oxyhydr)oxides (Ottley et al., 1997). In soils, clay minerals and oxides make up a significant fraction of the active surface area, and most natural clay minerals contain some structural Fe. Such reduced clay mineral particles (mainly by bacteria) have been found in a large range of soil types from many parts of the world. Redox processes involving such structural Fe(II) may, therefore, play an important role in the reduction of nitrates and other pollutants.

The oxidation state of structural $\mathrm{Fe}$ has a profound impact on the physical and chemical properties of clay minerals (Stucki, 2006; Stucki et al., 1988, 2002, 2007), including cation exchange and fixation capacity (Chen et al., 1987; Khaled and Stucki, 1991; Shen and Stucki, 1994), surface area ((Lear and Stucki, 1989; Kostka et al., 1999), surface pH (Cervini-Silva et al., 2000), and swelling in water (Stucki et al., 1984b; Gates et al., 1993; Gates et al., 1998). Any number of these properties could influence the reactivity of clay minerals toward the reduction of nitrate.

In studies reported by Ernstsen (1996) and Ernstsen et al. (1998), a sharp drop in nitrate levels between the oxic and anoxic zones of Danish soil profiles was found. The drop was explained by an abiotic pathway for nitrate depletion attributed to nitrate reduction by $\mathrm{Fe}$ (II) in the reduced clay mineral fraction (no evidence of microbial denitrification was found) (Ernstsen, 1996). Hansen and co-workers suggested that the active mineral may have been green rust (layered Fe(II)-Fe(III) oxyhydroxide), which is known to exist in soils but is difficult to characterize because of sensitivity to oxygen (Hansen et al., 1996, 2001; Hansen and Koch, 1998). Indeed, in laboratory studies, they demonstrated that synthetic forms of green rust can be an effective reductant of nitrate. Hofstetter et al. (2002) found that both structural $\mathrm{Fe}(\mathrm{II})$ and $\mathrm{Fe}(\mathrm{II})$ complexed by surface hydroxyl groups of nontronite were able to reduce nitroaromatic compounds (which can act as analogs for nitrate) to anilines. A reasonable assumption, based on these results, is that the clay minerals play a significant role in the nitrogen cycle, but no further studies have been reported on the reactivity of $\mathrm{Fe}$-bearing clay minerals toward nitrate reduction.

In the current study, the abiotic reduction of nitrate in chemically reduced ferruginous smectite (SWa-1) was studied. Preliminary results (Zachary B. Day, unpublished M.S. thesis, University of Illinois) found little or no reaction between aqueous nitrate and the reduced form of $\mathrm{Na}^{+}-\mathrm{SWa}-1$. This was attributed to coulombic repulsion between the negatively charged smectite surface and the nitrate anion. This repulsion clearly inhibited any redox interaction between the reduced smectite and the nitrate.

Polymer-modified clay minerals have received increasing attention as potential nano-composites for surface applications (Breen and Watson, 1998; Breen, 1999; Churchman, 2002b; Chang and Juang, 2004; RuizHitzky et al., 2005; Huskic et al., 2009; Letaief and Detellier, 2009). Polycations are well established as being able to intercalate into the interlayer of montmorillonite and neutralize or reverse the surface charge in smectites (Breen, 1999; Churchman, 2002b; Claesson et al., 2005; Radian and Mishael, 2008). For example, the application of chitosan-clay mineral composites as electrochemical sensors and anion-exchange resins has been explored and their selectivity toward nitrate has been reported (Darder et al., 2005; Ruiz-Hitzky et al., 2005; Darder et al., 2006). Bleiman and Mishael (2010) designed positively charged chitosan-clay mineral composites to form internal anion-exchange sites in partially exfoliated clay mineral structures, which resulted in significant adsorption of anionic forms of selenate.

In the present study, in order to overcome the coulombic repulsion, the smectite was exchanged with polydiallyldimethylammonium (poly-DADMAC) cations, which created positively charged surfaces on the smectite, causing them to be more attractive for nitrate adsorption. Consequently, nitrate abiotic reduction to nitrite by the structural $\mathrm{Fe}$ (II) in the redoxmodified smectite layer was established. These novel redox-activated organoclays have both adsorption and reduction properties which enable both immobilization and reductive degradation of redox-active pollutants.

\section{MATERIALS AND METHODS}

\section{Materials}

Ferruginous smectite (SWa-1 from Grant County, Washington, USA) was obtained from the Source Clays Repository of The Clay Minerals Society. The $<2 \mu \mathrm{m}$ particle-size fraction of SWa-1 was separated and $\mathrm{Na}^{+}$ saturated, then freeze dried before use. More details about the characterization of this mineral were reported by Manceau et al. (2000) and its unit-cell formula is $\mathrm{Na}_{0.87}\left(\mathrm{Si}_{7.38} \mathrm{Al}_{0.62}\right)\left(\mathrm{Al}_{1.08} \mathrm{Fe}_{2.67}^{3+} \mathrm{Fe}_{0.01}^{2+} \mathrm{Mg}_{0.23}\right) \mathrm{O}_{20}(\mathrm{OH})$.

Chemicals. All chemicals used were analytical-reagent grade, except sodium dithionite $\left(\mathrm{Na}_{2} \mathrm{~S}_{2} \mathrm{O}_{4}\right)$, which was technical grade, and were purchased from Fisher Scientific. Polydiallyldimethylammonium chloride (poly-DADMAC), average molecular weight of 200,000-350,000 Da, was obtained from SigmaAldrich (Stenheim, Germany, and St. Louis, Missouri, USA). This polymer was selected because previous 
experience (Radian and Mishael, 2008) has indicated that it is capable of reversing the effective charge in smectites from negative to positive, it has a high selectivity for smectite surfaces, and it is relatively easy to handle in aqueous systems. The positively charged sites of this poly cation are initially neutralized by $\mathrm{Cl}^{-}$, but upon adsorption to the smectite, some or many of them become neutralized instead by the negatively charged surface.

\section{Methods}

Preparation of poly-DADMAC-SWa-1. Poly-DADMAC solutions were prepared by adding $0,0.75,2.5,5.0$, or $10 \mathrm{~mL}$ of a $3 \mathrm{~g} / \mathrm{L}$ stock solution to a $50 \mathrm{~mL}$ polycarbonate centrifuge tube, then diluting to $20 \mathrm{~mL}$ with distilled (DI) water $(18 \mathrm{MOhm}-\mathrm{cm})$. To each of these solutions, $10 \mathrm{~mL}$ of a $5 \mathrm{~g} / \mathrm{L} \mathrm{Na}^{+}-\mathrm{SWa}-1$ suspension was added. The amount of SWa-1 in each tube was $50 \mathrm{mg}$ and the final poly-DADMAC concentration in the tubes was $0,0.075,0.25,0.50$, or $1.0 \mathrm{~g} / \mathrm{L}$ (Table 1 ). These samples were designated as $\mathrm{C} 0, \mathrm{C} 1, \mathrm{C} 2, \mathrm{C} 3$, and $\mathrm{C} 4$, respectively. Note that $\mathrm{C} 0$ with a polyDADMAC:SWa-1 mass ratio of $0 \mathrm{~g} / \mathrm{g}$ was unmodified $\mathrm{Na}^{+}$-SWa-1, which served as a reference or background sample. The other poly-DADMAC-SWa-1 samples were then mixed by shaking on a horizontal shaker for $2 \mathrm{~h}$ until equilibrium was reached, as described by Radian and Mishael (2008). After equilibration, samples were centrifuged, decanted, and freeze dried, except the samples to receive $\mathrm{NaNO}_{3}$ solution were not freeze dried. The net amount of poly-DADMAC adsorbed in freeze-dried samples was determined as the mass ratio of polymer to clay by a CHNSO analyzer (Fisons Model EA 110, Ipswich, UK).

$X R D$ measurements. The effects of different loadings of poly-DADMAC on the basal spacings of SWa-1 were measured by powder X-ray diffraction (XRD) on airdried, oriented samples using a Philips PW1830/3710/ 3020 diffractometer $(\mathrm{CuK} \alpha$ radiation, $\lambda=1.5418)$. Oriented clay mineral samples were prepared by redispersing a portion of freeze-dried, polymerexchanged samples in DI water, then drying 1 to $2 \mathrm{~mL}$ of clay mineral dispersions onto glass slides in air.
FTIR measurements. In the current study, Fouriertransform infrared (FTIR) measurements were obtained to establish the nature of interactions between the smectite surface and the polymeric cation. Freeze-dried samples of SWa-1, the respective poly-DADMACexchanged SWa-1 samples, and pure poly-DADMAC were prepared as $\mathrm{KBr}$ pellets (2 mg sample with $100 \mathrm{mg}$ $\mathrm{KBr}$ ) and analyzed using a Nicolet Magna-IR-550 spectrometer (Madison, Wisconsin). All FTIR spectra were recorded at room temperature using 100 scans/ spectrum in the range $400-4000 \mathrm{~cm}^{-1}$ with a $4 \mathrm{~cm}^{-1}$ resolution.

$\zeta$-potential measurements. The electrostatic zeta $(\zeta)$ potential, which is the potential at the shear plane, was chosen to represent the effective surface charge of the samples, and was measured at room temperature using a Zetasizer Nanosystem (Malvern Instruments, Southborough, Massachusetts, USA). Freeze-dried polymer-exchanged samples were re-dispersed in DI water at a solid-to-liquid concentration of $1.7 \mathrm{~g} / \mathrm{L}$. After dispersing, the samples were allowed to settle for $\sim 5 \mathrm{~min}$ and $\sim 1 \mathrm{~mL}$ of dispersion from the top of the tube was transferred to the measuring cuvette in the Zetasizer. The $\zeta$ potential was calculated from the electrophoretic mobility of the particles using the Smoluchowski equation

$$
\zeta=\frac{4 \mu \pi \eta}{\varepsilon}
$$

where $\mu$ is the measured electrophoretic mobility $(\mathrm{cm} / \mathrm{s} /$ unit field strength), $\eta$ is the viscosity of the solution phase (assumed to be 1 poise in this case), and $\varepsilon$ is the dielectric constant of the medium (assumed to be 80 and unitless).

Reduction of structural Fe in poly-DADMAC-SWa-1. The washed sample (containing $50 \mathrm{mg}$ of SWa-1) was centrifuged at $1400 \times \mathrm{g}$ (DuPont Sorvall Model RCM-5plus centrifuge with SS-34 rotor) and the supernatant discarded. The sample was then re-dispersed in $20 \mathrm{~mL}$ of DI water and $10 \mathrm{~mL}$ of C-B buffer solution prepared by combining $1.0 \mathrm{M}$ sodium bicarbonate and $0.9 \mathrm{M}$ sodium citrate dihydrate at a ratio of $24: 1$. The centrifuge

Table 1. Adsorption of polyallyldimethylammonium chloride (poly-DADMAC) to oxidized SWa-1.

\begin{tabular}{|c|c|c|c|c|c|}
\hline \multirow[t]{2}{*}{ Sample } & \multicolumn{2}{|c|}{ - poly-DADMAC added - } & \multicolumn{3}{|c|}{ — poly-DADMAC at equilibrium -} \\
\hline & $\begin{array}{l}\text { Concentration of } \\
\text { added solution } \\
(\mathrm{g} / \mathrm{L})\end{array}$ & $\begin{array}{c}\text { Mass ratio } \\
\text { to } \mathrm{SWa}-1 \\
(\mathrm{~g} / \mathrm{g})\end{array}$ & $\begin{array}{l}\text { Adsorbed } \\
\text { to } \mathrm{SWa}-1 \\
(\mathrm{~g} / \mathrm{g})\end{array}$ & $\begin{array}{c}\text { Fraction of } \\
\text { CEC adsorbed } \\
(\%)\end{array}$ & 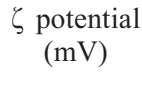 \\
\hline $\mathrm{CO}$ & 0 & 0 & 0 & 0 & -23.7 \\
\hline $\mathrm{C} 1$ & 0.075 & 0.045 & 0.044 & 43 & 12.4 \\
\hline $\mathrm{C} 2$ & 0.250 & 0.150 & 0.130 & 103 & 32.1 \\
\hline $\mathrm{C} 3$ & 0.500 & 0.299 & 0.200 & 198 & 51.8 \\
\hline $\mathrm{C} 4$ & 1.00 & 0.600 & 0.250 & 248 & 57.0 \\
\hline
\end{tabular}


reaction tube and contents were sealed with a septumequipped screw cap (Stucki et al., 1984a, 2013) and placed in a water bath at $70^{\circ} \mathrm{C}$. An $\mathrm{O}_{2}$-free $\mathrm{Ar}$ gas purge was then applied to each dispersion by inserting a supply needle (deflected point, $15 \mathrm{~cm}, 22$ gauge) through the septum into the dispersion and a vent needle (deflected point, $5 \mathrm{~cm}, 22$ gauge) into the head space above the dispersion. Once the temperature was reached and the purge was established, the screw cap was removed briefly and $200 \mathrm{mg}$ of solid sodium dithionite was added to begin chemical reduction of structural $\mathrm{Fe}$ in the sample. The tube was immediately re-closed with the screw cap and purge gas continued to flow. Unreduced samples were treated identically except $200 \mathrm{mg}$ of solid sodium sulfate was added instead of sodium dithionite. The reaction was allowed to proceed for $4 \mathrm{~h}$ at $70^{\circ} \mathrm{C}$, then the tube was removed from the water bath and cooled at room temperature for $1 \mathrm{~h}$ with purge gas flowing. During the reduction reaction, anions associated with the reacted dithionite and sulfate could have replaced some of the chloride in the poly-DADMAC on the smectite surfaces. The system was restored to its homoionically exchanged state with chloride by centrifuge washing with $\mathrm{O}_{2}$-free $1 \mathrm{M}(1$ time) and $0.005 \mathrm{M}(3$ to 5 times) $\mathrm{NaCl}$ solutions. The washings were carried out using a DuPont Sorvall Model RCM-5-plus centrifuge (SS-34 rotor) at $1400 \times \mathrm{g}$ and with the aid of a controlled-atmosphere liquid exchanger (CALE) (Stucki et al., 2013) to prevent re-oxidation of reduced samples.

Nitrate reduction by poly-DADMAC-SWa-1. After washing, $35 \mathrm{~mL}$ of $\mathrm{O}_{2}$-free $1.0 \mathrm{mM} \mathrm{NaNO}$ solution was added to the poly-DADMAC-exchanged SWa-1 dispersion via the CALE apparatus (nominally $0.03 \mathrm{mmole}$ $\mathrm{NO}_{3}^{-}$added to $50 \mathrm{mg}$ of smectite), and allowed to react for $12 \mathrm{~h}$ at room temperature on an oscillating shaker at 75 to $80 \mathrm{rpm}$. After the reaction, solutions were separated from the solids by centrifugation at $4525 \times \mathrm{g}$ and both the solid and solution phases were saved using the CALE apparatus.

For nitrogen analysis, solutions were filtered through a $0.22-\mu \mathrm{m}$ nitrocellulose membrane (Millipore, USA), then analyzed for three forms of nitrogen, namely, ammonium, nitrate plus nitrite, and nitrate only, using the accelerated diffusion method (Khan et al., 1997; Mulvaney et al., 1997). In this method, $\mathrm{NH}_{4}^{+}$in the sample solution was liberated as $\mathrm{NH}_{3}$ by heating to $50^{\circ} \mathrm{C}$ in the presence of $\mathrm{MgO}$. The $\mathrm{NH}_{3}$ was then captured into a boric acid indicator solution (boric acid + bromocresol green + methyl red) which shared the same enclosed atmosphere as the sample. This reaction changed the $\mathrm{pH}$ of the boric acid solution. The amount of $\mathrm{NH}_{3}$ captured was determined by back titrating the $\mathrm{NH}_{3}$-boric acid solution with $\mathrm{H}_{2} \mathrm{SO}_{4}$ to reach the end point, using an automatic titrator (Metrohm model 916 Ti-touch, Switzerland). Nitrate plus nitrite in the sample solution were converted to $\mathrm{NH}_{4}^{+}$by adding Devarda's alloy.
Nitrate only was determined by pre-treating the sample solution with sulfamic acid $(0.2 \mathrm{M})$, which was selective for destroying nitrite. The amount of nitrite in sample solutions was then calculated as the difference between nitrate plus nitrite and nitrate only.

Changes in oxidation state of structural $\mathrm{Fe}$ in the poly-DADMAC-exchanged SWa-1 were measured by analyzing samples before and after reaction with $\mathrm{NO}_{3}^{-}$ using the 1,10-phenanthroline method (Komadel and Stucki, 1988). The separated solid phase was kept inside the septum-sealed reaction tube until ready for oxidation state analysis, at which time the septum-sealing cap was removed and reagents $(12 \mathrm{~mL} 3.6 \mathrm{~N}$ sulfuric acid, $2 \mathrm{~mL}$ $10 \%(\mathrm{w} / \mathrm{w})$ 1,10-phenanthroline monohydrate in $95 \%$ ethanol, and $1 \mathrm{~mL} 48 \%$ hydrofluoric acid, in that order) were added immediately under red light. They were heated for $30 \mathrm{~min}$ in a boiling water bath, cooled for $15 \mathrm{~min}$ at room temperature, received $10 \mathrm{~mL} \mathrm{5 \% (w/w)}$ boric acid to remove excess $\mathrm{F}^{-}$, and then diluted with DI water. Further diluted aliquots (using a Dosimat 665, Metrohm, Switzerland) were then analyzed for $\mathrm{Fe}(\mathrm{II})$ at $510 \mathrm{~nm}$ (Varian Cary 5E UV-Vis-NIR spectrophotometer). Total $\mathrm{Fe}$ was measured after exposing the samples to ultra-violet light for $2 \mathrm{~h}$ (Stucki, 1981; Stucki and Anderson, 1981; Komadel and Stucki, 1988).

\section{RESULTS AND DISCUSSION}

Reaction of $\mathrm{NaNO}_{3}$ with the unreduced $\mathrm{Na}^{+}-\mathrm{SWa}-1$ (C0) showed no measurable nitrate adsorption (Figure 1), which was attributed to the lack of electrostatic compatibility. Because Fe was in its oxidized state in this sample, no nitrite was formed either. Reaction of $\mathrm{NaNO}_{3}$ with the reduced form of sample $\mathrm{C} 0$ did show a small amount of nitrate adsorption (Figure 1) and a trace of nitrite formed. These levels were very small, however, and affirmed the preliminary expectation that the abiotic reduction pathway of nitrate by clay minerals

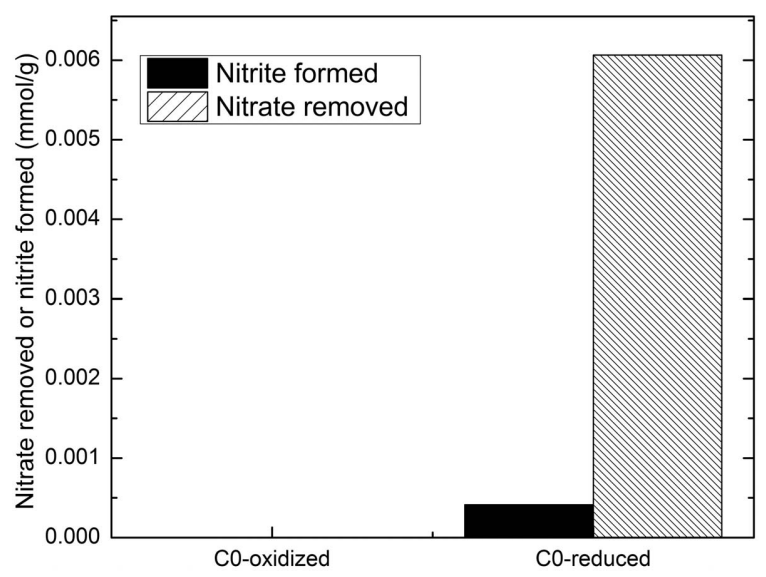

Figure 1. Nitrate removal and nitrite formation by unaltered (oxidized) (std. dev. $= \pm 0$ ) and reduced $\mathrm{Na}^{+}$-SWa-1 (sample $\mathrm{C} 0$ ). (std. dev. $= \pm 0.006 \mathrm{mmol}$ nitrate $/ \mathrm{g}$ and $0.0004 \mathrm{mmol} \mathrm{nitrite} / \mathrm{g}$ ). 
would be greatly hindered by electrostatic repulsion of nitrate by the negatively charged, smectite basal surface. The small reactions observed were probably the result of adsorption to positively charged sites at the edges of the clay mineral layers.

The attraction of nitrate was greatly enhanced by the adsorption of poly-DADMAC on the ferruginous smectite SWa-1 (Figure 2, Table 1). The selectivity of the polycation for surface-exchange sites was very high due to the electrostatic compatibility as reported previously (Durand-Piana et al., 1987; Tekin et al., 2006). At low concentrations of polycation, up to the CEC of the SWa1 (80 meq/100 g), adsorption was complete (samples C1 and $\mathrm{C} 2$ ). Adsorption continued to be high at concentrations exceeding the $\mathrm{CEC}$, reaching an exchanged amount of $0.25 \mathrm{~g} / \mathrm{g}$, corresponding to $\sim 250 \%$ of the CEC (sample C4).

The XRD patterns of air-dried samples with increased amounts of poly-DADMAC added to SWa-1 (Figure 3) revealed steady increases in the $d$ value from $1.24 \mathrm{~nm}$ for $\mathrm{C} 0$ to $1.47 \mathrm{~nm}$ for $\mathrm{C} 4$, confirming that the polycation had successfully entered the SWa-1 interlayers. Similar increases in intercalation at low polymer concentrations were observed by Churchman (2002a) and Yue et al. (2007).

Fourier-transform infrared spectroscopy provided further insight into the interaction of poly-DADMAC with the smectite surface (Figure 4). The characteristic peak at $2084 \mathrm{~cm}^{-1}$ present in the pure poly-DADMAC, attributed to $R-\mathrm{NH}_{3}^{+} \mathrm{Cl}^{-}$ammonium-chloride interactions (where $R$ represents unspecified $\mathrm{C}$ functional groups) (Colthup, 1950; Radian and Mishael, 2008), disappeared completely upon clay mineral intercalation, which indicates that the smectite and poly-DADMAC interacted through the $R-\mathrm{NH}_{3}^{+}$groups (Radian and Mishael, 2008). Peaks observed in the $2800-3000 \mathrm{~cm}^{-1}$ range

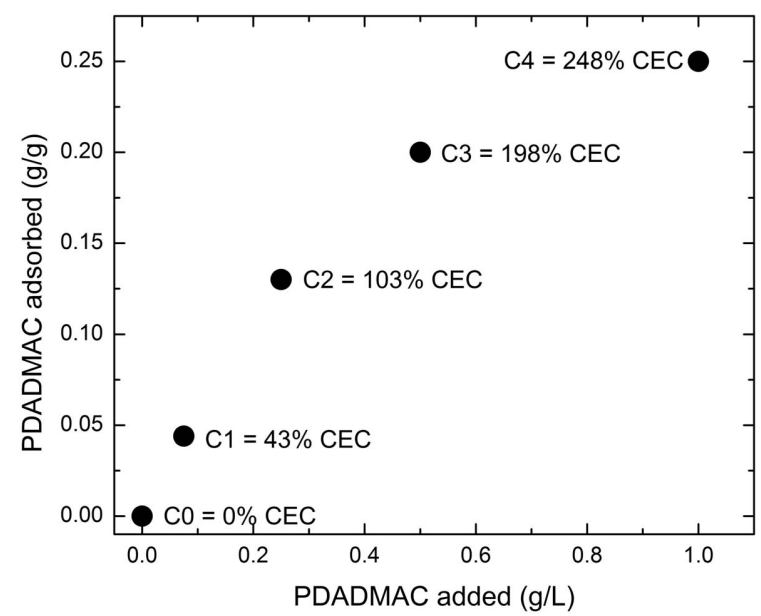

Figure 2. Adsorption of poly-DADMAC $(0-1 \mathrm{~g} / \mathrm{L}$ added $)$ on unaltered (oxidized) SWa-1 (1.67 g/L) smectite samples C0 to $\mathrm{C} 4$, expressed as both the gravimetric amount adsorbed (std. dev. $= \pm 0.03 \mathrm{~g} / \mathrm{g}$ ) and the fraction of CEC adsorbed.

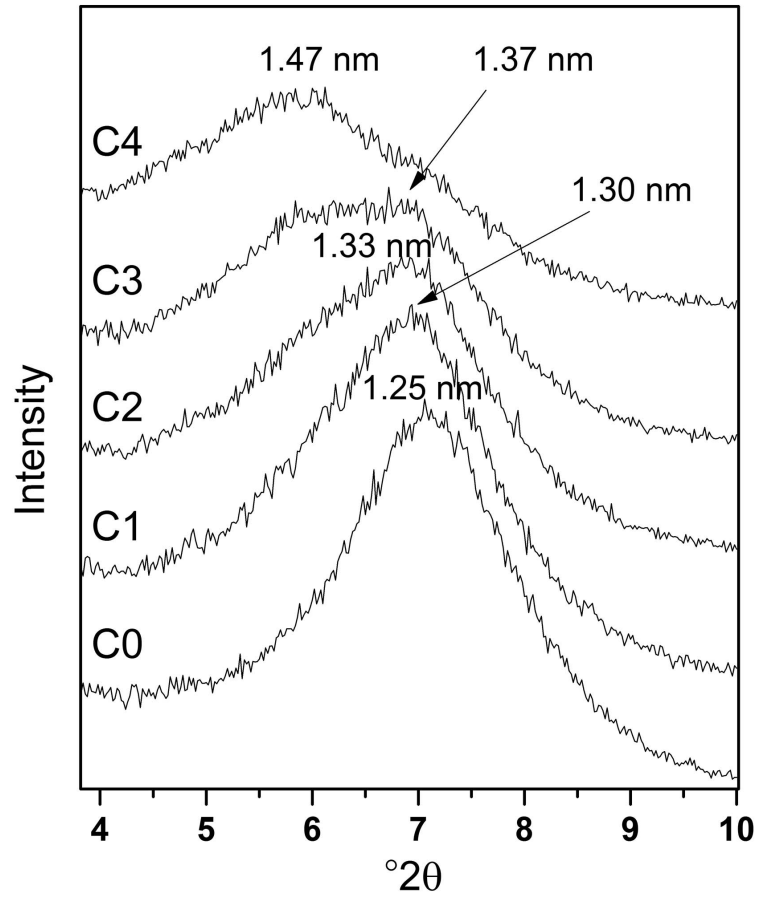

Figure 3. XRD patterns of oxidized or unaltered (oxidized) samples $\mathrm{C} 0$ to $\mathrm{C} 4$.

and near $1480 \mathrm{~cm}^{-1}$ were attributed to $\mathrm{CH}_{2}$ or $\mathrm{CH}_{3}$ stretching and bending vibrations of the poly-DADMAC. These peaks were unaffected by poly-DADMAC intercalation and indicated that the $\mathrm{CH}_{2}$ or $\mathrm{CH}_{3}$ groups did not interact with the smectite surface.

Polymer adsorption to the smectite was also monitored as a function of $\zeta$ potential (Figure 5). In the unaltered $\mathrm{Na}^{+}$-SWa-1 (sample $\mathrm{C} 0$ ), the $\zeta$ potential was negative, $-23.7 \mathrm{mV}$, as expected for smectites. In the poly-DADMAC-exchanged SWa-1 (samples $\mathrm{C} 1-\mathrm{C} 4$ ),

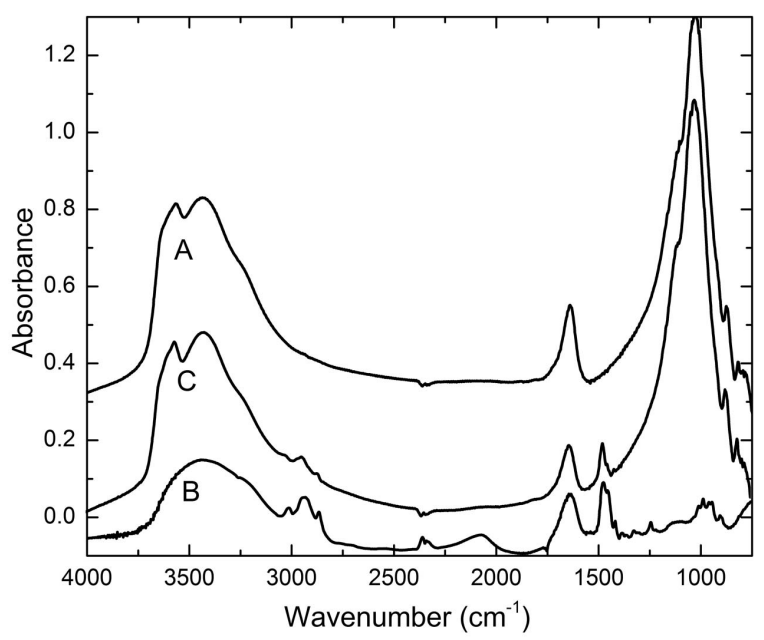

Figure 4. FTIR spectra of (A) $\mathrm{Na}^{+}-\mathrm{SWa}-1$, (B) pure polyDADMAC, and (C) poly-DADMAC-SWa-1 sample C4, all in the unaltered (oxidized) state. 
the $\zeta$ potential was reversed from negative to positive (Figure 5, Table 1) due to the positively charged polymer $(\zeta$ potential $=60 \mathrm{mV})($ Radian and Mishael, 2008). This change occurred even at the lowest concentration of polymer loading (sample C1) and became increasingly positive as the loading increased (samples C2-C4). Stoichiometric calculations suggested that electrical neutrality should have been reached at a poly-DADMAC loading of $0.11 \mathrm{~g} / \mathrm{g}$, but it was reached instead at the low concentration of $0.03 \mathrm{~g} / \mathrm{g}$. This apparent inconsistency may be explained by the positively charged polymer screening the surface charge of the smectite even at a very low loading, as has been reported previously in other studies (Radian and Mishael, 2008; Zadaka et al., 2010).

\section{Nitrate reaction with oxidized poly-DADMAC-SWa-1}

Adsorption of the poly-DADMAC onto the Febearing smectite, along with the accompanying changes in the effective surface charge from negative to positive, also greatly increased the attraction of the smectite for nitrate (Figure 5). In sharp contrast to sample $\mathrm{C} 0$ baseline observations (Figure 1), the oxidized $\mathrm{C} 1-\mathrm{C} 4$ poly-DADMAC-SWa-1 reacted strongly with nitrate and increased nitrate removal from solution (Figure 5). The amount of nitrate removed from solution was assumed to be equal to the amount of nitrate adsorbed. Nitrate adsorption by the oxidized poly-DADMAC-SWa-1 samples increased steadily with increases in polymer loading and reached $0.22 \mathrm{mmol} / \mathrm{g}$ for sample C4. Nitrate adsorption levels to the poly-DADMAC-SWa-1 were consistent with the $\zeta$ potentials and demonstrated that a positive surface charge facilitated anionic nitrogen species adsorption to the modified SWa-1 surfaces.

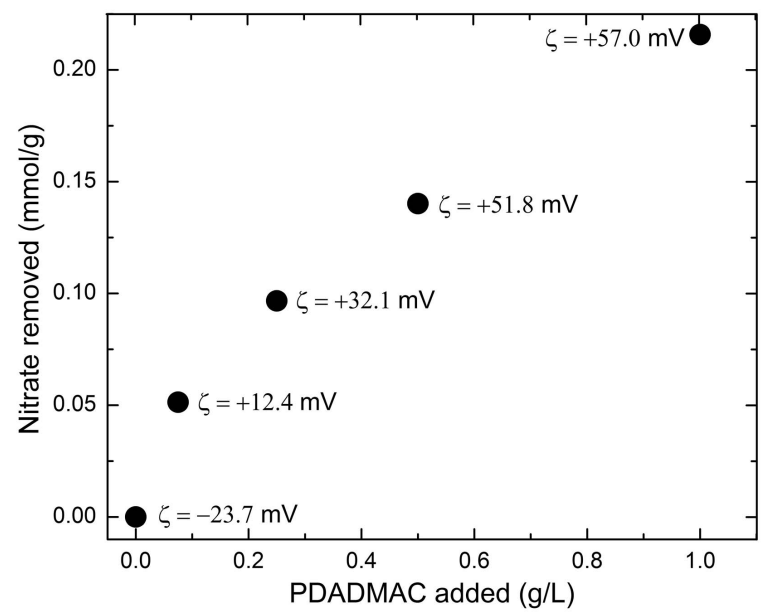

Figure 5. Zeta $(\zeta)$ potential (std. dev $= \pm 7 \mathrm{mV}$ ) measurements and amount of nitrate removed from solution by the oxidized forms of the poly-DADMAC-SWa-1 samples C0 to C4. (std. dev. $(\mathrm{mmol} / \mathrm{g}): \mathrm{C} 0=0, \mathrm{C} 1=0.0036, \mathrm{C} 2=0.0079, \mathrm{C} 3=0.0035, \mathrm{C} 4=$ $0.0024)$.
Nitrate reaction with reduced poly-DADMAC-SWa-1

The reduced samples also exhibited increased attraction for nitrate compared to the baseline reduced sample (compare Figure 6 with Figure 1). The amount of nitrate removed increased directly with the polymer loading, similar to what was observed in the oxidized samples, with a maximum of $\sim 0.19 \mathrm{mmol} / \mathrm{g}$ being reached in reduced $\mathrm{C} 4$. The method for reduction of structural $\mathrm{Fe}$ in the polymer-exchanged samples apparently had little effect on their ability to remove nitrate from solution. This adsorption ability provides direct evidence that the effective surface charge of the reduced poly-DADMACSWa-1 samples remained positive, even though the reduction of structural $\mathrm{Fe}$ increases the net negative charge on the smectite. The $\zeta$ potentials of polyDADMAC-SWa-1 samples in the reduced state, however, were not measured.

An important distinction between the oxidized and reduced forms of the poly-DADMAC-SWa-1 samples was that adsorption was the only type of interaction between nitrate and the oxidized poly-DADMAC-SWa1 , whereas in the reduced forms of poly-DADMACSWa-1 both adsorption and reductive degradation of nitrate occurred. A plot of nitrite in solution $v s$. Fe(II) oxidized (Figure 7) revealed a redox reaction between nitrate and the structural $\mathrm{Fe}(\mathrm{II})$ in the reduced forms of poly-DADMAC-SWa-1. The proposed process is that the positively charged surface of the reduced polyDADMAC-SWa-1 sample attracted nitrate, which then reacted with structural $\mathrm{Fe}$ (II) to form reduced $\mathrm{N}$ products. The coupled increases in nitrite in solution with oxidation of structural $\mathrm{Fe}(\mathrm{II})$ were direct evidence of this redox reaction.

The overall reaction stoichiometry in reduced polyDADMAC-SWa-1 suggested, however, that other com-

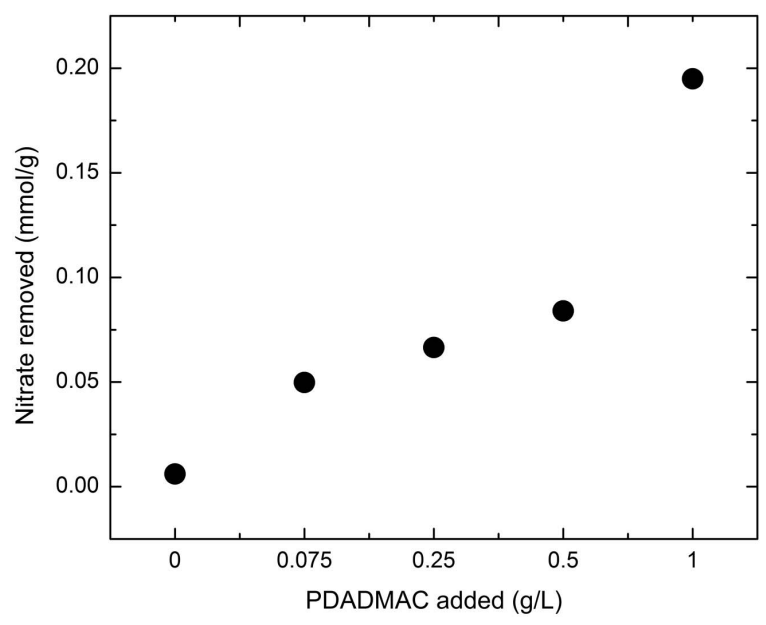

Figure 6. Nitrate removed from solution by reduced polyDADMAC-SWa-1 (std. dev. $(\mathrm{mmol} / \mathrm{g})$ : $\mathrm{C} 0=0.006, \mathrm{C} 1=0.001$, $\mathrm{C} 2=0.005, \mathrm{C} 3=0.003, \mathrm{C} 4=0.006)$. 


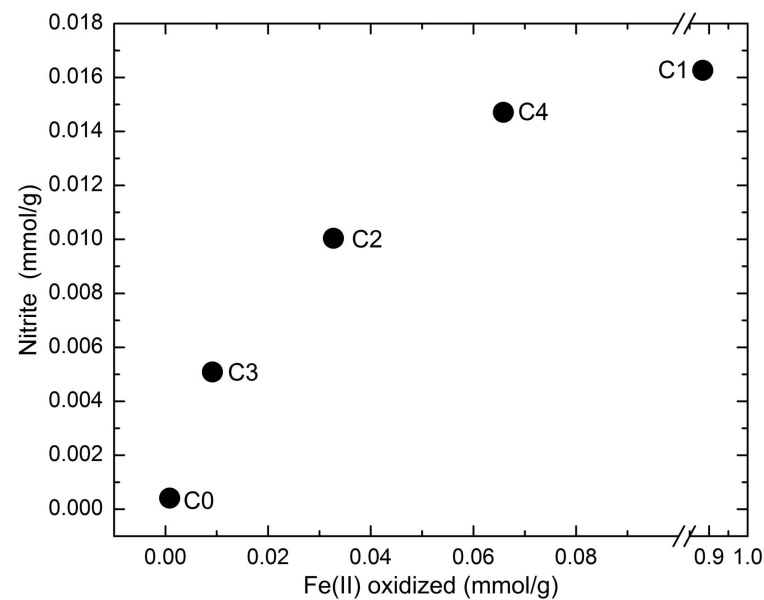

Figure 7. Nitrite formation (mmole nitrite in solution per $g$ of poly-DADMAC-SWa-1) as a function of $\mathrm{Fe}(\mathrm{II})$ oxidation (mmole $\mathrm{Fe}(\mathrm{II})$ per $\mathrm{g}$ of poly-DADMAC-SWa-1) in reduced poly-DADMAC-SWa-1 (nitrite std. dev. $(\mathrm{mmol} / \mathrm{g}): \mathrm{C} 0=0.0004$, $\mathrm{C} 1=0.0140, \mathrm{C} 2=0.0025, \mathrm{C} 3=0.0010, \mathrm{C} 4=0.0070 ; \mathrm{Fe}(\mathrm{II}) \mathrm{std}$. dev. $(\mathrm{mmol} / \mathrm{g}): \mathrm{C} 0=0.090, \mathrm{C} 1=0.200, \mathrm{C} 2=0.001, \mathrm{C} 3=0.009$, $\mathrm{C} 4=0.027)$.

plexities are involved. Reduction of nitrate to nitrite is a two-electron reduction reaction, and, if coupled with the oxidation of structural $\mathrm{Fe}(\mathrm{II})$ to $\mathrm{Fe}(\mathrm{III})$, has the stoichiometry of $2 \mathrm{Fe}(\mathrm{II})+\mathrm{N}^{5+} \rightarrow 2 \mathrm{Fe}(\mathrm{III})+\mathrm{N}^{3+}$. The stoichiometry ratio of $\mathrm{Fe}(\mathrm{II})$ :nitrite should, therefore, be $2: 1$. The observed ratio (Figure 7) varied from $2: 1$ to $80: 1$. This means that, even though a redox couple existed between the two principal reactants, the nitrite found in solution failed to always account for all of the $\mathrm{Fe}(\mathrm{II})$ oxidized. This could be explained by (1) nitrite in solution represented only a fraction of the nitrite actually formed, the remainder being adsorbed to the polymer on the surface; (2) other $\mathrm{N}$ reduction products (e.g. $\mathrm{N}_{2}$, $\mathrm{N}_{2} \mathrm{O}$ ) were also formed but not measured; (3) some $\mathrm{Fe}(\mathrm{II})$ oxidation occurred by other oxidizing agents such as traces of dissolved $\mathrm{O}_{2}$; and/or (4) nitrate access to the smectite $\mathrm{Fe}(\mathrm{II})$ was affected by the poly-DADMAC in unknown ways.

Evidence to support explanation 4 may be found by a closer examination of the data for Figure 7. Note that increased $\mathrm{Fe}(\mathrm{II})$ oxidation and nitrite formation do not follow the increased poly-DADMAC loading. Nitrite created from adsorbed nitrate decreased from 32.6 to $6.1 \%$ with increased polymer loading (Figure 8). One explanation for this behavior could be to assume that electron transfer from structural $\mathrm{Fe}(\mathrm{II})$ to nitrate does not occur through the polymer, but from the uncovered smectite surface. If this were the case, at low polyDADMAC loadings the smectite surface area accessible for electron transfer would be larger and the nitrate could more easily approach $\mathrm{Fe}(\mathrm{II})$ and be reduced. At high polymer loadings $(250 \%$ of CEC), the clay mineral surface would be mostly covered by poly-DADMAC, which might inhibit electron transfer and nitrate reduction.

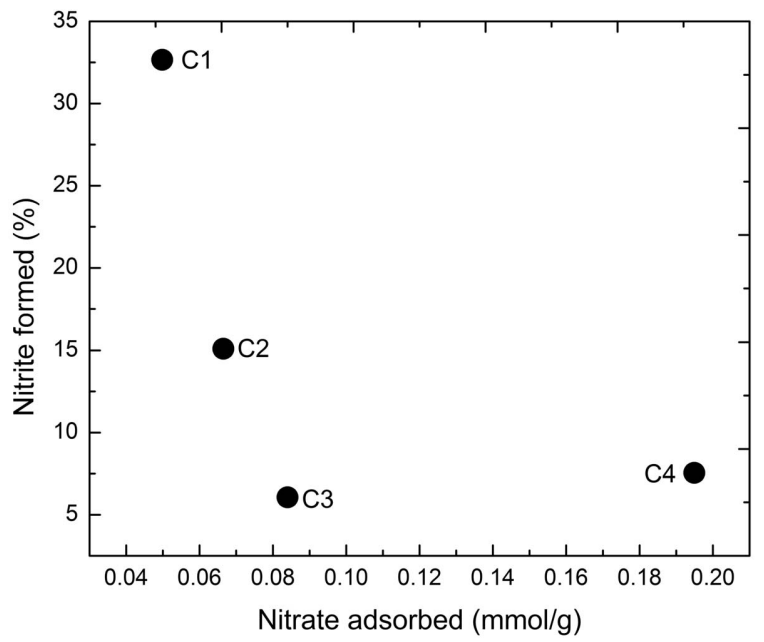

Figure 8. Nitrite in solution (as \% of nitrate adsorbed) as a function of nitrate adsorbed in reduced samples $\mathrm{C} 0$ to $\mathrm{C} 4$.

Future studies will address facets of the above complexities. In the meantime, observations reported here establish firm evidence of redox reactions between the reduced poly-DADMAC-SWa-1 and nitrate in solution. While specific implementation of this type of technology for environmental remediation has yet to be demonstrated, combining these observations with the facts that microbial activity effectively reduces structural $\mathrm{Fe}$ in smectites in soils and sediments and polymeric organic cations are abundant in soil organic matter suggests that such technological applications are possible. These results will help focus further studies to develop such systems to exploit the redox activity of smectites to mitigate the adverse effects of nitrate and other anionic contaminants in natural waters and the environment.

\section{CONCLUSIONS}

Ferruginous smectite, SWa-1, modified with polydiallyldimethylammonium chloride (poly-DADMAC) exhibited a surface charge reversal from negative to positive, as measured by the $\zeta$ potential. The positive charge on poly-DADMAC-SWa-1 increased in proportion to poly-DADMAC loading and resulted in more efficient nitrate removal from solution. Reduction of structural $\mathrm{Fe}(\mathrm{III})$ to $\mathrm{Fe}(\mathrm{II})$ in the poly-DADMAC-SWa-1 samples before reaction with nitrate enabled a redox reaction between adsorbed nitrate and structural $\mathrm{Fe}(\mathrm{II})$. Multiple N reduction products were possible, but the one measured was nitrite. A direct relationship was found between nitrite in solution and structural Fe(II) oxidized, and indicated extensive nitrate reduction by the positively charged, cationic polymer-modified, reduced-Fe ferruginous smectite. The data further indicated that more $\mathrm{Fe}(\mathrm{II})$ was oxidized than that needed to form the observed amount of nitrite in solution, which suggested 
that other $\mathrm{N}$ reduction products may have formed and/or other reaction complexities were present.

These observations are consistent with the hypothesis that abiotic reduction of nitrate by clay minerals in natural soils, sediments, and water resources is possible, and they provide knowledge upon which practical strategies for nitrate remediation can be achieved. The reduction of Fe in soil clay minerals may be a renewable resource for on-going nitrate degradation in the environment. These results using poly-DADMAC-exchanged SWa-1 could also lead to further studies to elucidate redox reactions between redox-activated smectites and other redox-active anionic species.

\section{ACKNOWLEDGMENTS}

The authors acknowledge financial support for this project from the National Science Foundation, Geobiology and Low-temperature Geochemistry Program Grant No. EAR-1148459. They also express appreciation to Professor Richard L. Mulvaney and Dr. Saed Kahn at the University of Illinois for helpful suggestions and laboratory assistance in $\mathrm{N}$ determinations, and to the Associate Editor and two anonymous reviewers whose service was timely and helpful.

\section{REFERENCES}

Alowitz, M.J. and Scherer, M.M. (2002) Kinetics of nitrate, nitrite, and $\mathrm{Cr}(\mathrm{VI})$ reduction by iron metal. Environmental Science \& Technology, 36, 299-306.

Baggs, E.M. (2011) Soil microbial sources of nitrous oxide: Recent advances in knowledge, emerging challenges and future direction. Current Opinion in Environmental Sustainability, 3, 321-327.

Bleiman, N. and Mishael, Y.G. (2010) Selenium removal from drinking water by adsorption to chitosan-clay composites and oxides: Batch and columns tests. Journal of Hazardous Materials, 183, 590-595.

Breen, C. (1999) The characterisation and use of polycationexchanged bentonites. Applied Clay Science, 15, 187-219.

Breen, C. and Watson, R. (1998) Polycation-exchanged clays as sorbents for organic pollutants: Influence of layer charge on pollutant sorption capacity. Journal of Colloid and Interface Science, 208, 422-429.

Burgin, A.J. and Hamilton, S.K. (2007) Have we overemphasized the role of denitrification in aquatic ecosystems? A review of nitrate removal pathways. Frontiers in Ecology and the Environment, 5, 89-96.

Camargo, J.A. and Alonso, A. (2006) Ecological and toxicological effects of inorganic nitrogen pollution in aquatic ecosystems: A global assessment. Environment International, 32, 831-849.

Cervini-Silva, J., Wu, J., Stucki, J.W., and Larson, R.A. (2000) Adsorption kinetics of pentachloroethane in iron-bearing smectites. Clays and Clay Minerals, 48, 132-138.

Chang, M.Y. and Juang, R.S. (2004) Adsorption of tannic acid, humic acid, and dyes from water using the composite of chitosan and activated clay. Journal of Colloid and Interface Science, 278, 18-25.

Chen, S.Z., Low, P.F., and Roth, C.B. (1987) Relation between potassium fixation and the oxidation-state of octahedral iron. Soil Science Society of America Journal, 51, 82-86.

Churchman, G.J. (2002a) Formation of complexes between bentonite and different cationic polyelectrolytes and their use as sorbents for non-ionic and anionic pollutants. Applied
Clay Science, 21, 177-189.

Churchman, G.J. (2002b) Formation of complexes between bentonite and different cationic polyelectrolytes and their use as sorbents for non-ionic and anionic pollutants. Applied Clay Science, 21, 177-189.

Claesson, P.M., Poptoshev, E., Blomberg, E., and Dedinaite, A. (2005) Polyelectrolyte-mediated surface interactions. Advances in Colloid and Interface Science, 114-115, $173-187$.

Colthup, N.B. (1950) Spectra-structure correlation in the infrared region. Journal of the Optical Society of America, 40, $397-400$.

Darder, M., Colilla, M., and Ruiz-Hitzky, E. (2005) Chitosanclay nanocomposites: Application as electrochemical sensors. Applied Clay Science, 28, 199-208.

Darder, M., Lopez-Blanco, M., Aranda, P., Aznar, A.J., Bravo, J., and Ruiz-Hitzky, E. (2006) Microfibrous chitosansepiolite nanocomposites. Chemistry of Materials, 18, $1602-1610$

Davidson, E.A., Chorover, J., and Dail, D.B. (2003) A mechanism of abiotic immobilization of nitrate in forest ecosystems: The ferrous wheel hypothesis. Global Change Biology, 9, 228-236.

Devlin, J.F., Eedy, R., and Butler, B.J. (2000) The effects of electron donor and granular iron on nitrate transformation rates in sediments from a municipal water supply aquifer. Journal of Contaminant Hydrology, 46, 81-97.

Durand-Piana, G., Lafuma, F., and Audebert, R. (1987) Flocculation and adsorption properties of cationic polyelectrolytes toward Na-montmorillonite dilute suspensions. Journal of Colloid and Interface Science, 119, 474-480.

EPA (1986) Quality criteria for water, edited by U. S. E. P. Agency, Washington, D.C.

Ernstsen, V. (1996) Reduction of nitrate by $\mathrm{Fe}^{2+}$ in clay minerals. Clays and Clay Minerals, 44, 599-608.

Ernstsen, V., Gates, W.P., and Stucki, J.W. (1998) Microbial reduction of structural iron in clays - a renewable source of reduction capacity. Journal of Environmental Quality, 27, $761-766$.

Gates, W.P., Wilkinson, H.T., and Stucki, J.W. (1993) Swelling properties of microbially reduced ferruginous smectite. Clays and Clay Minerals, 41, 360-364.

Gates, W.P., Jaunet, A.-M., Tessier, D., Cole, M.A., Wilkinson, H.T., and Stucki, J.W. (1998) Swelling and texture of iron-bearing smectites reduced by bacteria. Clays and Clay Minerals, 46, 487-497.

Hansen, H.C.B. and Koch, C.B. (1998) Reduction of nitrate to ammonium by sulphate green rust: Activation energy and reaction mechanism. Clay Minerals, 33, 87-101.

Hansen, H.C.B., Koch, C.B., Nanckekrogh, H., Borggaard, O.K., and Sorensen, J. (1996) Abiotic nitrate reduction to ammonium: Key role of green rust. Environmental Science \& Technology, 30, 2053-2056.

Hansen, H.C.B., Guldberg, S., Erbs, M., and Koch, C.B. (2001) Kinetics of nitrate reduction by green rusts - effects of interlayer anion and $\mathrm{Fe}(\mathrm{ii}) \mathrm{Fe}$ (iii) ratio. Applied Clay Science, 18, 81-91.

Hofstetter, T.B., Schwarzenbach, R.P., and Haderlein, S.B. (2002) Reactivity of $\mathrm{Fe}(\mathrm{II})$ species associated with clay minerals. Environmental Science \& Technology, 37, 519-528.

Huang, C.P., Wang, H.W., and Chiu, P.C. (1998) Nitrate reduction by metallic iron. Water Research, 32, 2257-2264.

Huskic, M., Zagar, E., Zigon, M., Brnardic, I., Macan, J., and Ivankovic, M. (2009) Modification of montmorillonite by cationic polyesters. Applied Clay Science, 43, 420-424.

Khaled, E.M. and Stucki, J.W. (1991) Fe oxidation state effects on cation fixation in smectites. Soil Science Society of America Journal, 55, 550-554. 
Khan, S.A., Mulvaney, R.L., and Mulvaney, C.S. (1997) Accelerated diffusion methods for inorganic-nitrogen analysis of soil extracts and water. Soil Science Society of America Journal, 61, 936-942.

Komadel, P. and Stucki, J.W. (1988) Quantitative assay of minerals for $\mathrm{Fe}^{2+}$ and $\mathrm{Fe}^{3+}$ using 1,10-phenanthroline. 3. A rapid photochemical method. Clays and Clay Minerals, 36, 379-381.

Kostka, J.E., Wu, J., Nealson, K.H., and Stucki, J.W. (1999) The impact of structural Fe(III) reduction by bacteria on the surface chemistry of smectite clay minerals. Geochimica et Cosmochimica Acta, 63, 3705-3713.

Lear, P.R. and Stucki, J.W. (1989) Effects of iron oxidation state on the specific surface area of nontronite. Clays and Clay Minerals, 37, 547-552.

Letaief, S. and Detellier, C. (2009) Clay-polymer nanocomposite material from the delamination of kaolinite in the presence of sodium polyacrylate. Langmuir, 25, 10975-10979.

Manceau, A., Lanson, B., Drits, V.A., Chateigner, D., Gates, W.P., Wu, J., Huo, D., and Stucki, J.W. (2000) Oxidationreduction mechanism of iron in dioctahedral smectites: I. Crystal chemistry of oxidized reference nontronites. American Mineralogist, 85, 133-152.

Miehr, R., Tratnyek, P.G., Bandstra, J.Z., Scherer, M.M., Alowitz, M.J., and Byłaska, E.J. (2004) Diversity of contaminant reduction reactions by zerovalent iron: Role of the reductate. Environmental Science \& Technology, 38, 139-147.

Mulvaney, R.L., Khan, S.A., Stevens, W.B., and Mulvaney, C.S. (1997) Improved diffusion methods for determination of inorganic nitrogen in soil extracts and water. Biology and Fertility of Soils, 24, 413-420.

Ottley, C.J., Davison, W., and Edmunds, W.M. (1997) Chemical catalysis of nitrate reduction by iron(II). Geochimica et Cosmochimica Acta, 61, 1819-1828.

Radian, A. and Mishael, Y.G. (2008) Characterizing and designing polycation-clay nanocomposites as a basis for imazapyr controlled release formulations. Environmental Science \& Technology, 42, 1511-1516.

Rivett, M.O., Buss, S.R., Morgan, P., Smith, J.W.N., and Bemment, C.D. (2008) Nitrate attenuation in groundwater: A review of biogeochemical controlling processes. Water Research, 42, 4215-4232.

Ruiz-Hitzky, E.R., Darder, M., and Aranda, P. (2005) Functional biopolymer nanocomposites based on layered solids. Journal of Materials Chemistry, 15, 3650-3662.

Seitzinger, S.P. (1988) Denitrification in freshwater and coastal marine ecosystems: Ecological and geochemical significance. Limnology and Oceanography, 33, 702-724.

Shen, S. and Stucki, J.W. (1994) Effects of iron oxidation state on the fate and behavior of potassium in soils. Pp. 173-185 in: Soil Testing: Prospects for Improving Nutrient Recommendations (J.L. Havlin and J. Jacobsen, editors). Soil Science Society of America, Madison, Wisconsin, USA.

Siantar, D.P., Schreier, C.G., Chou, C.S., and Reinhard, M. (1996) Treatment of 1,2-dibromo-3-chloropropane and nitrate-contaminated water with zero-valent iron or hydrogen/palladium catalysts. Water Research, 30, 2315-2322.

Sohn, K., Kang, S.W., Ahn, S., Woo, M., and Yang, S.K. (2006) $\mathrm{Fe}(0)$ nanoparticles for nitrate reduction: Stability, reactivity, and transformation. Environmental Science \& Technology, 40, 5514-5519.
Stucki, J.W. (1981) The quantitative assay of minerals for $\mathrm{Fe}^{2+}$ and $\mathrm{Fe}^{3+}$ using 1,10-phenanthroline. 2. A photochemical method. Soil Science Society of America Journal, 45, $638-641$.

Stucki, J.W. (2006) Properties and behavior of iron in clay minerals. Pp. 429-482 in: Handbook of Clay Science (F. Bergaya, B.K.G. Theng, and G. Lagaly, editors). Elsevier, Amsterdam.

Stucki, J.W. and Anderson, W.L. (1981) The quantitative assay of minerals for $\mathrm{Fe}^{2+}$ and $\mathrm{Fe}^{3+}$ using 1,10-phenanthroline. 1. Sources of variability. Soil Science Society of America Journal, 45, 633-637.

Stucki, J.W., Golden, D.C., and Roth, C.B. (1984a) Preparation and handling of dithionite-reduced smectite suspensions. Clays and Clay Minerals, 32, 191-197.

Stucki, J.W., Low, P.F., Roth, C.B., and Golden, D.C. (1984b) Effects of oxidation state of octahedral iron on clay swelling. Clays and Clay Minerals, 32, 357-362.

Stucki, J.W., Goodman, B.A., and Schwertmann, U. (1988) Iron in Soils and Clay Minerals. D. Reidel, Dordrecht, The Netherlands, $980 \mathrm{pp}$.

Stucki, J.W., Lee, K., Zhang, L.Z., and Larson, R.A. (2002) Effects of iron oxidation state on the surface and structural properties of smectites. Pure and Applied Chemistry, 74, 2145-2158.

Stucki, J.W., Lee, K., Goodman, B.A., and Kostka, J.E. (2007) Effects of in situ biostimulation on iron mineral speciation in a sub-surface soil. Geochimica et Cosmochimica Acta, 71, $835-843$.

Stucki, J.W., Pentrak, M., Su, K., and Pentrakova, L. (2013) Controlled atmosphere methods for redox-activated smectites. Clay Minerals, 47, (submitted).

Tekin, N., Kadinci, E., Demirbas, O., Alkan, M., and Kara, A. (2006) Adsorption of polyvinylimidazole onto kaolinite. Journal of Colloid and Interface Science, 296, 472-479.

Tiedje, J.M. (1988) Ecology of denitrification and dissimilatory nitrate reduction to ammonium. Pp. 179-244 in: Biology of Anaerobic Microorganisms (J.B.A. Zehnder, editor). John Wiley \& Sons, New York.

Till, B.A., Weathers, L.J., and Alvarez, P.J.J. (1998) Fe(0)supported autotrophic denitrification. Environmental Science \& Technology, 32, 634-639.

van Olphen, H. (1953) Interlayer forces in bentonite. Clays and Clay Minerals, 2, 418-438.

van Olphen, H. (1963) An Introduction to Clay Colloid Chemistry, Interscience, New York, $301 \mathrm{pp}$.

Westerhoff, P. (2003) Reduction of nitrate, bromate, and chlorate by zero valent iron (Fe-0). Journal of Environmental Engineering - ASCE, 129, 10-16.

WHO (1996) Guidelines for drinking-water quality. Health criteria and other supporting information. 2nd edition. World Health Organization, Geneva.

Yue, Q.Y., Li, Q., Gao, B.Y., Yuan, A.J., and Wang, Y. (2007) Formation and characteristics of cationic-polymer/bentonite complexes as adsorbents for dyes. Applied Clay Science, $\mathbf{3 5}$, $268-275$.

Zadaka, D., Radian, A., and Mishael, Y.G. (2010) Applying zeta potential measurements to characterize the adsorption on montmorillonite of organic cations as monomers, micelles, or polymers. Journal of Colloid and Interface Science, 352, 171-177.

(Received 20 August 2012; revised 2 October 2012; Ms 701; AE: R. Dohrmann) 